\title{
Pancreatic Blood Flow in Conscious Dogs after Oral Administration of Glucose
}

\author{
U. Fischer, H. Hommel and E. Salzsieder \\ Central Institute for Diabetes "G. Katsch", Karlsburg, German Democratic Republic
}

\begin{abstract}
Summary. Dogs with an electromagnetic flowprobe implanted around the superior pancreaticoduodenal artery and with an hydraulic occluder implanted upstream from the flowprobe were examined between the $3 \mathrm{rd}$ and the 8 th postoperative day. During an oral glucose load, blood flow increased from the beginning of administration to about 25 minutes, but not when blood glucose and plasma IRI exhibit their maxima. The rise of pancreatic blood flow is assumed to be produced by reflexes similar to those stimulating insulin secretion and exocrine pancreatic function during the early phase of an oral glucose load.
\end{abstract}

Key words: Pancreatic blood flow, oral glucose test, insulin secretion, reflex.

A transient dose-dependent increase of pancreatic blood supply after intravenous injection of glucose has been demonstrated by several methods: hydrogen gas clearance [23], venous outflow monitoring $[15,20]$, and electromagnetic measurement $[5,11]$. Such investigations have, however, not been done during an oral glucose load.

On the other hand pancreatic blood flow is correlated with pancreatic secretion of water and of enzymes $[1,9,13,14,24]$. Thus, redistribution of splanchnic blood flow after feeding is well known [14, $21,22]$. Insulin secretion however, is obviously independent of blood flow in the physiologic range of a diminished $[16,17,20]$ or of an elevated $[5,19]$ pancreatic perfusion. Some insulinogenic reflex independent of hyperglycemia has been shown in dogs after an oral glucose load [4]. Therefore the experiments reported here are to investigate pancreatic blood flow during an oral glucose tolerance test in conscious dogs and the relation of any blood flow alteration to hyperglycemia and to insulin secretion.

\section{Material and Methods}

\section{Animals and Preparation}

4 trained Alsatian dogs (mean age 30 months, body wt. $31 \mathrm{~kg}$ ) were used. They were fed once a day with $1000 \mathrm{~g}$ cooked beef plus $500 \mathrm{~g}$ bread [4].

After a median laparotomy under intubation anaesthesia, implantable electromagnetic flowprobes of an appropriate inner diameter $(2.2-2.5 \mathrm{~mm})$ were placed around the superior pancreaticoduodenal artery and secured with a slot-cover. Flow through this artery was demonstrated to supply about $60 \%$ of the pancreatic wet weight and to pass to other organs (pyloric and duodenal mucosal) at less than $5 \%$ [6]. For zero-flow adjustment, a self-constructed hydraulic occluder was placed in the hepatic artery about $5 \mathrm{~cm}$ upstream from the flowprobe.

It was also secured with a slot-cover. The occluding device made from plastics in the form of a flowprobe (wt. $2 \mathrm{~g}$ ) contains a teflon piston which is pushed from the outside via a tube filled with saline.

The nervous plexuses around the artery were carefully separated without any cutting, and the flowprobe introduced between the plexus and the artery. Both the cable of the flowprobe and the occlusion tubing were led through the abdominal cavity without any additional fixation. Via a subcutaneous channel on the left side they reached the back between the scapulae. Their extremities were secured in a skin-penetrating plastic capsule with a metallic grip.

The dogs had their usual feeding regime again after the 1 st postoperative day. They were sufficiently recovered and could be used for experiments from the 


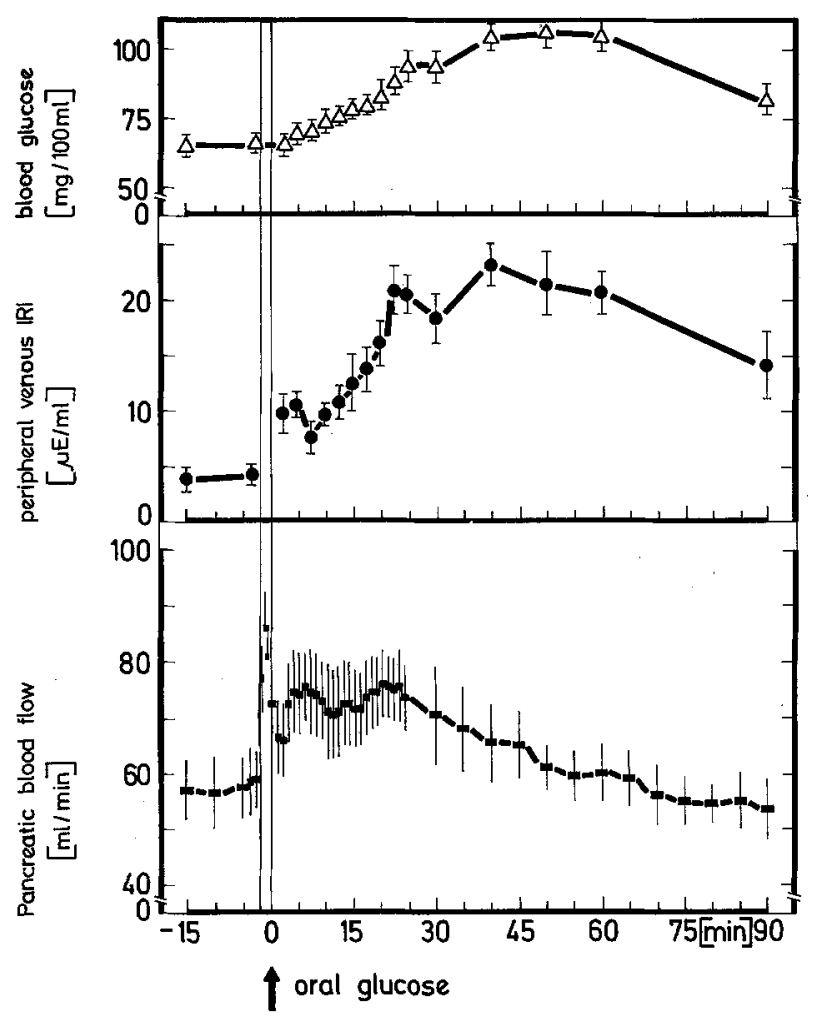

Fig. 1. Blood flow through the superior pancreaticoduodenal artery and peripheral venous concentrations of blood glucose and of plasma IRI before, during, and after oral administration of $1.0 \mathrm{~g} / \mathrm{kg}$ glucose in dogs implanted with flowprobes and occluding devices (10 experiments in 4 animals between day 3 and 8 after the operation)

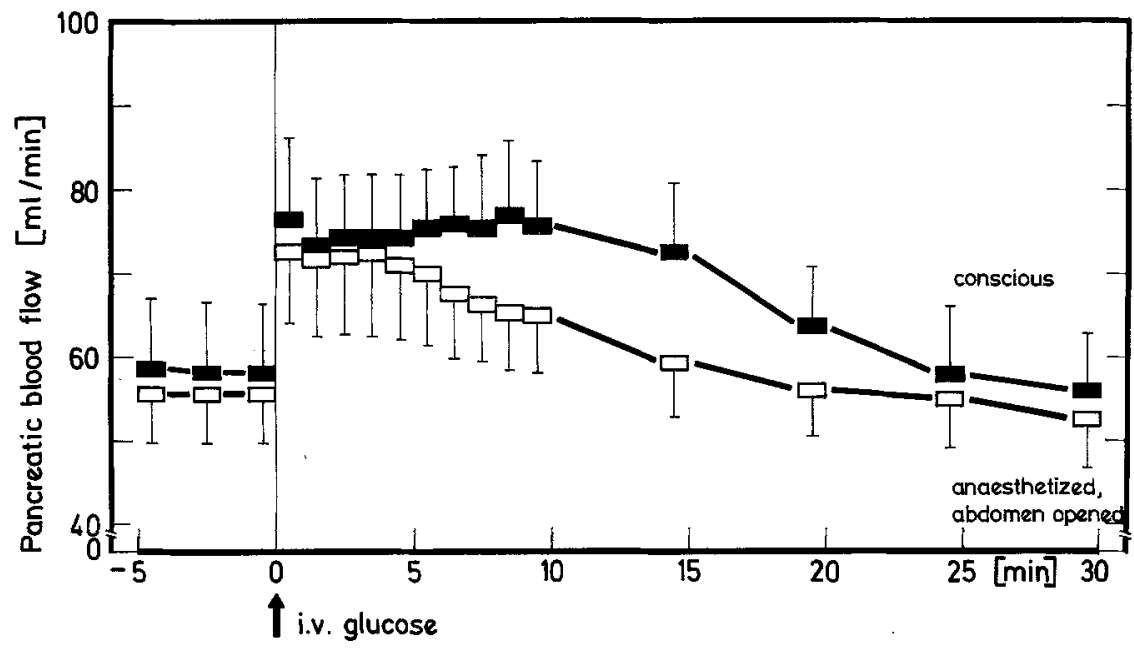

Fig. 2. Blood flow through the superior pancreaticoduodenal artery as measured by an electromagnetic flowmeter, before and after intravenous injection of glucose $(0.5 \mathrm{~g} / \mathrm{kg})$, in conscious dogs implanted with flowprobes and occluding devices $(8$ experiments in 4 animals between day

2 and 8 after the operation) and in anaesthetized laparotomized animals $(n=18)$, mean \pm SEM 3rd to the 8 th postoperative day. Termination of the experimental period was mainly caused by cable defects. No pathological histologic findings were seen on the pancreata.

\section{Experiments and Measurements}

$20 \mathrm{~h}$ after the last meal the animals standing in a Pavlov frame were loaded with $1.0 \mathrm{~g} / \mathrm{kg}$ glucose, dissolved in $50 \mathrm{ml}$ tap water, orally ( 2 or 3 experiments in each implanted animal; duration of feeding $2 \mathrm{~min}$ ) or with $0.5 \mathrm{~g} / \mathrm{kg}$ glucose intravenously as a $50 \mathrm{w} / \mathrm{v} \%$ solution ( 2 experiments in each animal). Blood flow of the superior pancreaticoduodenal artery was continuously monitored by a square-wave electromagnetic flowmeter (Nycotron A/S, Drammen, Norway). The flowprobes were calibrated in vivo. Controls of the appropriate adjustment for zero flow were repeatedly made before and during the tests. For demonstrating the results as a mean, the data were taken from selected points of the recordings.

After oral glucose administration the peripheral 
venous concentration of blood glucose was measured with glucose oxidase using o-dianisidine as a colour reagent, and plasma immunoreactive insulin activity (IRI) was estimated according to the back titration principle after alcohol precipitation (for the methods cf. 4). The mean \pm SEM of the measured values is given in the figures. For evaluating statistical significance the t-test was used $(\mathrm{p}<0.01)$.

\section{Results}

When glucose was given orally (Fig. 1) blood glucose was significantly raised only after $15 \mathrm{~min}$, and reaching a peak after $50 \mathrm{~min}$ with a concentration difference of about $40 \mathrm{mg} / 100 \mathrm{ml}$. Nevertheless, plasma IRI was significantly raised after $2.5 \mathrm{~min}$ with several peaks before reaching a maximum at 40 to $60 \mathrm{~min}$. These reactions do not differ from those in animals which were not actually operated on [4]. In all tests, blood flow through the superior pancreaticoduodenal artery started to increase immediately after the first swallowing of the glucose solution. In 3 tests on one animal, basal flow levels were reached again, but only transiently during the 5 min after the end of administration. After this, a further significant elevation was observed. Blood flow in each individual test was elevated by 15 to $30 \%(\mathrm{p}<0.01)$ between 5 and $20 \mathrm{~min}$. This is significantly earlier than the peaks of blood glucose and of plasma IRI. Blood flow started to normalize before blood glucose and IRI reached their maxima, and was normal after 55-70 min when both the other parameters were still elevated.

In Figure 2 the observations on these conscious postoperative animals are compared with those on 18 anaesthetized, laparotomized dogs (mean age $26 \pm 3$ months, body wt. $25 \pm 1 \mathrm{~kg}$, mean duration of anaesthesia $190 \mathrm{~min}$ ) previously published [5]. The mean basal flow through the superior pancreaticoduodenal artery was identical in conscious and in anaesthetized animals ( 50 to $60 \mathrm{ml} / \mathrm{min}$ ). Rapid elevation of blood glucose to about $300 \mathrm{mg} / 100 \mathrm{ml}$ by intravenous injection of glucose was accompanied by an elevated pancreatic blood flow normalizing within $30 \mathrm{~min}$. There was no difference in the reaction between the conscious implanted animals and the acutely laparotomized dogs.

Any systematic alteration of pancreatic blood flow as well as any strong dependence on the position of the animals and on exercise were excluded by a long-term continuous recording during the operation and in the immediate postoperative period. When comparing the individual tests there is no trend to diminish or to increase the basal flow levels or the responses to oral or to intravenous glucose in relation to time.

\section{Discussion}

Our observations demonstrate that pancreatic blood flow is increased when blood glucose is rapidly raised by intravenous administration of glucose. Peripheral vasodilatation seems to be a physiologic reaction to intravascular which is probably not specific for the pancreas $[5,11,15,20,23]$. It occurs equally in anaesthetized laparotomized dogs as well as in conscious implanted animals (Fig. 2). Thus our results in the latter group are assumed to be correct.

After oral glucose administration, plasma IRI rose during the first phase independently of any metabolic insulinogenic stimulus. This seems to be released by some reflex part of the enteroinsular axis [4]. Pancreatic blood flow also increased during this early phase (Fig. 1). In contrast to the extreme hyperglycemia of the intravenous glucose load, there was no relation of pancreatic blood flow to the small and more physiologic hyperglycemia of an oral glucose test.

Pancreatic vasodilatation is known to be produced by several agents stimulating exocrine volume and enzyme secretion $[1,12,24]$, especially by the gastrointestinal hormones secretin, gastrin, and pancreozymin-cholecystokinin $[3,8,12]$. Blood concentration of these gastrointestinal hormones is, however, not measurably increased during an oral glucose test (review: 2). Therefore, the early increase of pancreatic blood flow during such a test is assumed to be produced by a vagally mediated vasodilatation, as in the case of increased insulin secretion and exocrine pancreatic activity [7]. This would be consonant with pancreatic hyperemia after cholinergic stimulation $[9$, $10,12,24]$.

A primarily increased pancreatic blood flow can probably stimulate the volume secretion if a basal level of secretin is present [18]. But there is no alteration of insulin secretion when pancreatic blood flow is primarily increased by non-insulinogenic stimuli (5: intravenous infusion of mannitol). In the experiments reported here, IRI maxima were not related to the peaks of pancreatic blood flow. This suggests that increased pancreatic perfusion is not one of the mechanisms stimulating insulin secretion after an oral glucose test.

Acknowledgements. The histologic examination of the pancreases by Dr. Hahn von Dorsche, Anatomisches Institut of the Ernst-Moritz-Arndt-Universität Greifswald, is greatly appreciated. For skilful technical assistance we are grateful to Mrs. Karla Brüllke, Helga Schröder, Helga Goraczka and Hannelore Buff. 


\section{References}

1. Bennett, A. L., Still, E. U.: A study of the relation of pancreatic duct pressure to the rate of blood flow through the pancreas. Amer. J. Physiol. 106, 454-459 (1933)

2. Creutzfeldt, W.: Insulin-releasing factors of the gastrointestinal mucosa (incretin). Gastroenterology 67, 748-749 (1974)

3. Delaney, J. P., Grim, E.: Influence of hormones and drugs on canine pancreatic blood flow. Amer. J. Physiol. 211, 1398-1402 (1966)

4. Fischer, U., Hommel, H., Ziegler, M., Michael, R.: The mechanism of insulin secretion after oral glucose administration. I. Multiphasic course of insulin mobilization after oral administration of glucose in conscious dogs. Differences to the behaviour after intravenous administration. Diabetologia 8, 104-110 (1972)

5. Fischer, U., Hommel, H., Schmid, E.: Dynamics of canine pancreatic blood flow and of insulin secretion during an intravenous glucose load. Pflügers Arch. ges. Physiol. 358, 89-100 (1975)

6. Fischer, U., Hommel, H., Gottschling, D., Heinke, P., Jutzi, E.: Estimation of pancreatic IRI output rate and its relation to glucose tolerance in normal anaesthetized dogs. Diabetologia 11, 291-299 (1975)

7. Fischer, U., Hommel, H., Nowak, W., Sill, U., Lippert, H.: The mechanism of insulin secretion after oral glucose administration. VII. Exocrine pancreatic function and plasma IRI in dogs with chronic pancreatic fistulas. In preparation

8. Goodhead, B., Himal, H. S., Zanbilowicz, J.: Relationship between pancreatic secretion and pancreatic blood flow. Gut 11, 62-68 (1970)

9. Greenwell, J. R., Scratcherd, T.: The kinetics of pancreatic amylase secretion and its relationship to volume flow and electrical conductance in the anaesthetized cat. J. Physiol. (Lond.) 239, 443-457 (1974)

10. Hickson, J. C. D.: The secretion of pancreatic juice in response to stimulation of the vagus nerves in the pig. J. Physiol. (Lond.) 206, 275-297 (1970)

11. Hiebert, J. M., McCormick, J. M., Egdahl, H. E.: Direct measurement of insulin secretory rate: Studies in shocked primates and postoperative patients. Ann. Surg. 176, 296-303 (1971)

12. Holton, P., Jones, M.: Some observations on changes in the blood content of the cat's pancreas during activity. J. Physiol. (Lond.) 150, 479-488 (1960)

13. Jacobson, E. D.: The gastrointestinal circulation. Ann. Rev. Physiol. 30, 133-146 (1968)
14. Kuznetsova, K. E.: Characteristics of blood supply of the pancreas during different phases of its activity. Fiziol. Zh. (Mosk.) 48, 470-478 (1962)

15. Lefebvre, J. P., Luyckx, A. S.: Régulation de la sécrétion d'insuline par le pancréas de chien in situ. J. Ann. Diab. Hôtel-Dieu 10, 139-155 (1969)

16. Lefebvre, J. P., Luyckx, A. S.: Effect of ouabain on insulin secretion in the anaesthetized dog. Biochem. Pharmacol. 21, 339-345 (1972)

17. Lefebvre, J. P., Luyckx, A. S.: Stimulation of insulin secretion after prostaglandin $\mathrm{PGE}_{1}$ in the anaesthetized dog. Biochem. Pharmacol. 22, 1773-1779 (1973)

18. Lenninger, S.: Effects of acetylcholine and papaverine on the secretion and blood flow from the pancreas of the cat. Acta physiol. scand. 89, 260-268 (1973)

19. Mandelbaum, J., Morgan, C. R.: Pancreatic blood flow and its relationship to insulin secretion during extracorporeal circulation. Ann. Surg. 170, 753-758 (1969)

20. Porte, Jr., D., Girardier, L., Seydoux, J., Kanazawa, Y., Posternak, J.: Neural regulation of insulin secretion in the dog. J. clin. Invest. 52, 210-214 (1973)

21. Reininger, E. J., Sapirstein, L. A.: Effect of digestion on distribution of blood flow in the rat. Science 126, 1176-1176 (1957)

22. Rushmer, R. F., Franklin, D. L., van Citters, R. L., Smith, O. A.: Changes in peripheral blood flow distribution in healthy dogs. Circulat. Res. 9, 675-687 (1961)

23. Semb, L. S., Aune, S.: The effect of glucose and insulin on pancreatic blood flow in the anaesthetized pig. Scand. J. clin. Lab. Invest. 27, 105-111 (1971)

24. Tankel, H. I., Hollander, F.: The relation between pancreatic secretion and local blood flow. A review. Gastroenterology 32, 633-641 (1957)

Received: September 24, 1975, and in revised form: January 23, 1976

Dr. sc. med. U. Fischer

Dept. of Experimental Diabetes Research

Central Institute for Diabetes

"Gerhardt Katsch"

DDR-2201 Karlsburg

German Democratic Republic 